\title{
Factors associated with patient visits to the emergency department for asthma therapy
}

\author{
Hamdan AL-Jahdali ${ }^{1,4^{*}}$, Ahmed Anwar ${ }^{2}$, Abdullah AL-Harbi ${ }^{1}$, Salim Baharoon ${ }^{1}$, Rabih Halwani ${ }^{3}$, \\ Abdulllah Al Shimemeri ${ }^{1}$ and Saleh Al-Muhsen ${ }^{3}$
}

\begin{abstract}
Background: Acute asthma attacks remain a frequent cause of emergency department (ED) visits and hospital admission. Many factors encourage patients to seek asthma treatment at the emergency department. These factors may be related to the patient himself or to a health system that hinders asthma control. The aim of this study was to identify the main factors that lead to the frequent admission of asthmatic patients to the ED.
\end{abstract}

Methods: A cross-sectional survey of all the patients who visited the emergency room with bronchial asthma attacks over a 9-month period was undertaken at two major academic hospitals. The following data were collected: demographic data, asthma control in the preceding month, where and by whom the patients were treated, whether the patient received education about asthma or its medication and the patients' reasons for visiting the ED.

Result: Four hundred fifty $(N=450)$ patients were recruited, $39.1 \%$ of whom were males with a mean age of $42.3 \pm$ 16.7. The mean duration of asthma was $155.90 \pm 127.13$ weeks. Approximately half of the patients did not receive any information about bronchial asthma as a disease, and $40.7 \%$ did not receive any education regarding how to use asthma medication. Asthma was not controlled or partially controlled in the majority (97.7\%) of the patients preceding the admission to ED. The majority of the patients visited the ED to receive a bronchodilator by nebuliser (86.7\%) and to obtain oxygen (75.1\%). Moreover, $20.9 \%$ of the patients believed that the ED managed them faster than the clinic, and $21.1 \%$ claimed that their symptoms were severe enough that they could not wait for a clinic visit. No education about asthma and uncontrolled asthma are the major factors leading to frequent ED visits (three or more visits/year), $p$-value $=0.0145$ and $p$-value $=0.0003$, respectively. Asthma control also exhibited a significant relationship with inhaled corticosteroid ICS use ( $p$-value $=0.0401$ ) and education about asthma ( $p$-value $=0.0117$ ).

Conclusion: This study demonstrates that many avoidable risk factors lead to uncontrolled asthma and frequent ED visits.

Keywords: Asthma, Control, Inhaled cortisone, Emergency department

\section{Background}

Asthma is a common condition that affects $5-10 \%$ of the population. The incidence and prevalence of asthma have increased during the past 20 years [1,2]. The prevalence of bronchial asthma among Saudi patients is approximately $20-25 \%[2,3]$. Poor asthma control remains a frequent cause of emergency department (ED)

\footnotetext{
* Correspondence: Jahdalih@gmail.com

'Department of Medicine, Pulmonary Division-ICU, King Saud University for Health Sciences, Riyadh, Saudi Arabia

${ }^{4}$ Head of Pulmonary Division, Medical Director of Sleep Disorders Center, Adjunct professor McGill University, King Saud University for Health Sciences, King Abdulaziz Medical City, Riyadh, Riyadh, Saudi Arabia

Full list of author information is available at the end of the article
}

presentation and hospital admission [4]. The cost of uncontrolled asthma care is substantial. For example, the utilisation of the emergency department for asthma management accounts for almost one-third of all asthma costs in the United States [5].

There are many factors that lead patients to visit the ED. The most common reported factors include asthma severity, poor compliance, the inappropriate use of inhalers, incorrect perceptions about bronchial asthma as a disease or about its medication, the cost of medication, lack of an asthma action plan, comorbidities, over reliance on short acting bronchodilators, pollution and changes in the weather, the patient's level of education and low socioeconomic status [5-19].

\section{Biomed Central}


Reducing the use of the ED for acute asthma treatment remains a major goal of asthma management that is recommended by all guidelines [20-23]. It is not clear why many patients in our community still visit the ED and depends on the ED as their primary if not sole source of care. It is important to understand the factors associated with asthma-related ED visits in order to reduce the use of ED resource utilization for asthma treatment. There are many factors that encourage patients to seek asthma treatment at the ED and these factors may be different from one society to another. It is very important to identify characteristics of the patients and deficiencies in our health care delivery system related factors causing poor asthma control and frequent visits to the emergency department (ED). The objective of this study is to evaluate the most important factors associated with the increased usage of the emergency department in our population.

\section{Methods}

This was a cross-sectional study conducted at the King Abdulaziz Medical City- King Fahad National Guard Hospital in Riyadh (KAMC-KFNGH) and the King Khalid University Hospital (KKUH). We enrolled patients with diagnosis of asthma who visited the ED for asthma management between August 2010 and March 2011. The enrolled patient must have a documented diagnosis of bronchial asthma as diagnosed by their primary treating physician and on prescribed inhaled corticosteroid (ICS) for at least the last three months. We excluded patients with undocumented diagnosis of bronchial asthma and not on ICS as per their medical record. This study was approved by the IRBs of both hospitals (Ref. IRBC/123/11). During ED visit, the trained coinvestigator collected information about demographic data, the duration of the illness, the medication used for asthma therapy and if the patient received any formal asthma education about asthma as a disease, how to use their inhaler devices and by whom. The patients were asked about regular visits to outpatient clinics, where they followed up, and how many times they visited the emergency department or were hospitalised over the last year. Co-investigators also verify this information by reviewing the medical record of each patient and assess asthma control over the last month by administering validated published Arabic version of Asthma Control Test (ACT) [24].

\section{Statistical analysis}

The collected data were transferred and analyzed using $\mathrm{SAS}^{\circledR}$ version 9.2 (SAS Institute Inc., Cary, NC). Descriptive statistics, such as means, standard deviations, or median were used to summarize age and duration of asthma disease. Percentages were also used to summarize gender, ICS use, follow up with clinics, education level, educated about medication, educated about asthma, and reasons for visiting the ED. Mann-Whitney test was used to compare the distributions of asthma disease duration across number of asthma-related ED visits ( $<3$ vs. $\geq 3$ ). Chi squared tests were used to test the associations between gender, ICS use, follow up with clinics, education level, educated about medication, and educated about asthma across asthma-related ED visits. Similar analysis used for asthma control test (ACT). Multiple logistic models were used to identify the risk factors that associated with three or more asthma-related ED visits. Pvalues less than 0.05 were considered significant. The odds ratios (ORs) with 95\% CIs were reported to describe the strength of these associations.

\section{Results}

Four hundred fifty $(\mathrm{n}=450)$ asthma patients were enrolled in the study. Of the 450 asthma patients, 176 (39.1\%) were males and 274 (60.9\%) were females. The patient's demographic and clinical characteristics are shown in Table 1. The mean patients' age was 42.3 \pm 16.7 years, and the mean duration of asthma illness was $155.90 \pm 127.13$ weeks. Two hundred and seventy (60.0\%) patients were regularly followed up with a physician, while $180(40.0 \%)$ patients did not have any follow up arrangement after their initial diagnosis of asthma. Approximately half of the patients did not have any formal education about asthma 232 (51.6\%), while 183 (40.7\%) did not receive education about how to use the medication or the devices. Of 218 patients received information about asthma as a disease, $44.5 \%$ received this information from physicians, $7.8 \%$ received the information from asthma educators, and $4.7 \%$ received the information from a pharmacist. One hundred sixty five of the 450 patients $(36.7 \%)$ visited the ED three or more per year. The patients' asthma control for the last month before the ED visit was as follows: $23.4 \%$ of the patients with uncontrolled asthma (ACT score $\leq 15$ ), $74.4 \%$ of the patients with partial controlled asthma $(16 \leq \mathrm{ACT}$ score $\leq 23), 1.8 \%$ of the patients with complete controlled asthma (ACT score $\geq 24$ ), and $0.5 \%$ of the patients with missing ACT score. When the patients were asked about the reason for the ED visit, the majority of the patients $86.7 \%$ indicated that receiving a nebulised bronchodilator was the major reason. Three hundred thirty-eight (75.1\%) patients mentioned obtaining oxygen as their reason, while $20.9 \%$ believed that the ED treated their asthma faster, and $21.1 \%$ claimed that their asthma was severe enough that they could not wait to visit the clinic (Table 2). The majority of the patients, $74.7 \%$, did not know what triggered their asthma, and $81.6 \%$ stopped all asthma therapy once they felt better. 
Table 1 Patient demographics and clinical asthma characteristics $(\mathrm{N}=\mathbf{4 5 0})$

\begin{tabular}{|c|c|c|}
\hline Variable & Levels & \\
\hline Age, (Mean $\pm S D)$ & & $42.3 \pm 16.7$ \\
\hline Duration of illness in weeks (Mean \pm & $=S D)$ & $155.90 \pm 127.13)$ \\
\hline Gender & $\%$ Female & 60.9 \\
\hline Education level & No school & 44.0 \\
\hline & $\begin{array}{l}\text { High school or } \\
\text { less }\end{array}$ & 42.0 \\
\hline & University & 13.8 \\
\hline & Missing & 0.2 \\
\hline Employment Status & Employee & 31.8 \\
\hline & Student & 6.9 \\
\hline & Housewife & 52.0 \\
\hline & Non-employee & 4.7 \\
\hline & Other & 4.4 \\
\hline & Missing & 0.2 \\
\hline Follow up consistently with doctor & & 60.0 \\
\hline Follow-up clinic & $\begin{array}{l}\text { PHC/Family } \\
\text { Medicine }\end{array}$ & 46.2 \\
\hline & Pulmonary & 10.2 \\
\hline & Internal Medicine & 1.8 \\
\hline & Other & 1.8 \\
\hline & No follow-up & 40.0 \\
\hline No education about asthma & & 51.6 \\
\hline $\begin{array}{l}\text { No education about medication } \\
\text { (devices) }\end{array}$ & & 40.7 \\
\hline ED visits & $<3$ & 61.3 \\
\hline & $\geq 3$ & 36.7 \\
\hline & Missing & 2.0 \\
\hline Asthma control & Uncontrolled & 23.3 \\
\hline & $\begin{array}{l}\text { Partially } \\
\text { controlled }\end{array}$ & 74.4 \\
\hline & $\begin{array}{l}\text { Completely } \\
\text { control }\end{array}$ & 1.8 \\
\hline & Missing & 0.5 \\
\hline
\end{tabular}

$\bar{\pi}$ All percentage rounded to one decimal.

The asthma-related ED visits were classified on the basis of whether the asthma patient had three or more asthma-related ED visits. Table 3, shows the relationships between three or more asthma-related ED visits and the patient's education level, education about asthma, ISC, and asthma control. Those who were not educated about asthma were more likely to visit the ED because of asthma than those who had been educated about asthma $(42.7 \%$ versus $31.5 \%$, p-value $=0.0145)$. More of the patients with uncontrolled asthma (ACT score $\leq 15$ ) than partially/fully controlled asthma (ACT score $>15)$ made three or more ED visits $(52.4 \%$ versus
$32.9 \%, \mathrm{p}$-value $=0.0003)$. Table 4 , shows the relationships between asthma control and patient's demographic and clinical characteristics. There was a relationship between patient believe of needing oxygen for asthma therapy and three or more ED visits (40.5\% versus $28.2 \%$, $\mathrm{p}$-value $=0.0209$ ), there was no relationship between visit ED primarily to obtain a bronchodilator and three or more ED visits $(36.5 \%$ versus $43.3 \%$, p-value $=0.3081)$. Mann-Whitney test revealed there was no relationship between the duration of the disease and the number of ED visit $(p=0.3944)$. An education level higher than high school $(\mathrm{p}$-value $=0.0071)$, an uncontrolled asthma (p-value $=0.0063)$, and irregular follow up with clinics $(p$-value $=0.0328)$ were highly associated with three or more asthma-related ED visits, after being controlled for gender, ICS use, education level, education about medication, and education about asthma (Table 5). As found in this study, the patients with university education were twice more likely to visit the ED than the patients with high school or not educated (OR: 2.359; 95\% CI: 1.263, 4.407). The patients with uncontrolled asthma were twice as likely to come to the ED compared with the patients with controlled asthma (OR: 1.924; 95\% CI: 1.203, 3.077). This study also showed that asthma control as determined by ACT had a significant relationship with ICS use ( $\mathrm{p}$-value $=0.0401)$, asthma education ( $\mathrm{p}$-value $=0.0117)$, ED visit primarily to obtain a bronchodilator ( $\mathrm{p}$-value $=0.0001$ ), and $\mathrm{ED}$ visit to obtain oxygen ( $p$-value $=0.0203$ ). The distribution of uncontrolled asthma varied depending on patient ICS use (27.6\% irregular, while $19.4 \%$ regular use). Those who had not been educated about asthma were more likely to have uncontrolled asthma than those who had been educated about asthma (28.1\% versus $18.1 \%)$.

\section{Discussion}

While this study is not epidemiological, it is the first study to investigate the factors leading to ED visits in a sample of Saudi bronchial asthma population and the characteristics of those patients. The major strength of this study lies in direct interviewing the patients and confirmation of the information obtained by reviewing the medical record. It is very important to examine these factors, because, we observed that many patients depend on the ED for asthma management. Knowing these factors may help address some of the deficiencies in our health system. The national and international guidelines for the management of bronchial asthma emphasise patient education and regular follow up with asthma professional. Our study generally showed that a substantial number of patients do not follow up asthma management with physicians and did not receive any education about asthma as a disease. A substantial number of our patients also used ED as an easy way to access their 
Table 2 Knowledge about asthma management and Reasons for visiting the ED ( $N=450)$

\begin{tabular}{ll}
\hline Variable & $\%$ \\
\hline Reason for ED visit & 86.7 \\
Visit ED primarily to obtain a bronchodilator & 75.1 \\
Visit ED to obtain oxygen & 21.1 \\
The severity of asthma doesn't allow the patient to wait for a & \\
Clinic visit. & 20.9 \\
Belief that the patient is treated faster in the ED & 19.1 \\
The ED is available 24 hours a day & 20.9 \\
The patient treated directly without delay & 19.6 \\
Medication given as nebulizer at ED is more useful & 87.3 \\
Knowledge about asthma management & 81.6 \\
Take bronchodilator to relieve symptoms only & 42.7 \\
Stop ICS therapy when feel better & 35.1 \\
Believe long term use of inhaler unsafe & 40.3 \\
Believe continues use of inhaler cause dependence & 74.7 \\
Believe asthma therapy use its effect overtime & 28.9 \\
Does not know what trigger asthma symptoms & \\
Does not know what should do during asthma attack &
\end{tabular}

$\bar{\pi}$ All percentage rounded to one decimal.

asthma management instead of keeping a follow up appointment with asthma professionals. This is not unique for our population, and many studies have reported the same findings $[14,15,25]$. The majority of our patients exhibited uncontrolled or partially controlled bronchial asthma (97.7\%) in the months preceding the ED visit, which is unacceptably high. However, this result also consistent with our previous finding of a substantial percentage of uncontrolled or partially controlled bronchial asthma (95\%) among the patients in major tertiary care hospitals [26]. The result of our study raises national concerns regarding our current asthma management system, which requires better health delivery structures, easy clinic access for patients, better patient education, better dissemination of the current national asthma guidelines and better monitoring. Asthma educators only educated $17 \%$ of the patients in this study; this was primarily due to the lack of trained asthma educators in many tertiary care hospitals and definitely contributes to the number of patients with uncontrolled asthma and the number of ED visits. The majority of our patients who had follow up visits (40\%) attended the follow up at a primary care clinic, where the setting for asthma education is not very strong. The lack of patients education about asthma is obvious, as almost $40 \%$ of our patients were never taught how to use asthma devices. Studies have shown that ensuring that asthma patients understand their medication and the appropriate use of a drug delivery device contributes significantly to asthma control [27-30]. Furthermore, Hanania NA et al. [31] have shown that many of the medical personnel responsible for instructing and educating patients in optimal inhaler use lack rudimentary skills with these devices, seldom receive formal training in the use of inhalation devices, and may be not familiar with newer inhalation devices and techniques. We believe that our study identify probably a substantial problem in our health care system, particularly in the primary care setting. Abudahish, A et al. [32] have shown that asthma management in primary care is unsatisfactory. Our study also revealed

Table 3 The association between asthma-related ED visits and demographic and clinical characteristics $(\mathrm{N}=441)$

\begin{tabular}{|c|c|c|c|c|}
\hline \multirow[t]{2}{*}{ Variable } & \multirow[t]{2}{*}{ Levels } & $<3$ visits & \multirow{2}{*}{$\frac{\geq 3 \text { visits }}{(n=165)}$} & \multirow{2}{*}{$\begin{array}{r}p \\
\text { value }\end{array}$} \\
\hline & & $\overline{(n=276)}$ & & \\
\hline \multirow[t]{2}{*}{ Gender } & $\%$ Male & 63.8 & 36.2 & 0.6721 \\
\hline & Female & 61.8 & 38.2 & \\
\hline \multirow[t]{2}{*}{ Regular ICS use } & Yes & 65.6 & 34.4 & 0.1880 \\
\hline & No & 59.6 & 40.4 & \\
\hline \multirow[t]{2}{*}{ Follow up with clinics } & Yes & 61.4 & 38.6 & 0.4688 \\
\hline & No & 64.8 & 35.2 & \\
\hline \multirow[t]{2}{*}{ Education level } & High school or less & 64.8 & 35.2 & $0.0133^{*}$ \\
\hline & University & 48.4 & 51.6 & \\
\hline \multirow[t]{2}{*}{ Educated about medication } & Yes & 64.5 & 35.5 & 0.3498 \\
\hline & No & 60.1 & 39.9 & \\
\hline \multirow[t]{2}{*}{ Educated about asthma } & Yes & 68.5 & 31.5 & $0.0145^{*}$ \\
\hline & No & 57.3 & 42.7 & \\
\hline \multirow[t]{2}{*}{ ACT } & Not controlled & 47.6 & 52.4 & $0.0003^{*}$ \\
\hline & Partially/Full controlled & 67.1 & 32.9 & \\
\hline
\end{tabular}

*The Chi-square statistic is significant at the .05 level. $\bar{\top} A l l$ percentage rounded to one decimal. 
Table 4 The association between the asthma control test (ACT) and demographic and clinical characteristics $(\mathrm{N}=448)$

\begin{tabular}{|c|c|c|c|c|}
\hline Variable & Levels & Partially/Full controlled $(n=343)$ & Not controlled $(n=105)$ & $p$-value \\
\hline \multirow[t]{2}{*}{ Gender } & $\%$ Male & 76.0 & 24.0 & 0.8220 \\
\hline & Female & 76.9 & 23.1 & \\
\hline \multirow[t]{2}{*}{ Regular ICS use } & Yes & 80.6 & 19.4 & $0.0401^{*}$ \\
\hline & No & 72.4 & 27.6 & \\
\hline \multirow[t]{2}{*}{ Follow up with clinics } & Yes & 77.8 & 22.2 & 0.5188 \\
\hline & No & 75.1 & 24.9 & \\
\hline \multirow[t]{2}{*}{ Education level } & High school or less & 77.2 & 22.8 & 0.3853 \\
\hline & University & 72.1 & 27.9 & \\
\hline \multirow[t]{2}{*}{ Educated about medication } & Yes & 78.6 & 21.4 & 0.2650 \\
\hline & No & 74.0 & 26.0 & \\
\hline \multirow[t]{2}{*}{ Educated about asthma } & Yes & 81.9 & 18.1 & $0.0117^{*}$ \\
\hline & No & 71.9 & 28.1 & \\
\hline
\end{tabular}

${ }^{*}$ The Chi-square statistic is significant at the .05 level. ${ }^{\pi} A l l$ percentage rounded to one decimal.

the common misunderstanding of using the ED to receive a nebulised bronchodilator and oxygen as primary therapy for acute asthma among many of our patients. Approximately $80 \%$ of the patients were classified with mild asthma by the National Asthma Educating Program (NAEAP), and these patients would probably obtain relief from their symptoms by using rescue MDI bronchodilator without need to visit ED if they received the appropriate education. We also examined the factors that lead to three or more ED visits over the preceding year, believing that patients with frequent ED visits probably have less control over their asthma. In our study, the more educated patients reported three or more ED visits; however, the number of these patients was generally small (13\%), and most of them experienced moderate to severe asthma (data not shown). Similar to other studies investigating the lack of asthma education, uncontrolled or partially controlled asthma were major reasons for the ED visit, in addition to inconsistent clinic visits $[15,16]$. This study is only based on two teaching hospitals in the central region of Saudi
Arabia and may not reflect the situation at the national level. However, we believe that this study reflects the current general characteristics and risk factors for crisis oriented care and dependence on the ED for the management of bronchial asthma exacerbations. Furthermore, the situation may be even worse if we assessed these data at the country level, where the infrastructure for asthma management may be less well organised.

\section{Limitations}

One of the major limitations of this study is the inability to assess the components or quality of the different asthma education or information programs our asthmatic patients received from health care professionals. In addition, we did not examine the detailed risk factors for asthma exacerbation, such as an environmental risk for exacerbations at home or in working environments. The second limitation is the lack of an economic evaluation for an ED visit. While the Saudi Arabian government provides free health care for all Saudi citizens, we could not readily assess the accessibility of outpatient

Table 5 The odds ratios and $\mathbf{9 5 \%}$ Cls for the risk factors associated with three or more asthma-related ED visits

\begin{tabular}{|c|c|c|c|c|c|c|}
\hline Variable & levels & Estimate & P-value & OR & & \\
\hline Intercept & & -0.2487 & 0.3982 & - & - & - \\
\hline Age & & 0.00344 & 0.5984 & 1.003 & 0.991 & 1.016 \\
\hline Gender & Female & 0.0694 & 0.5192 & 1.149 & 0.753 & 1.752 \\
\hline Regular ICS use & No & 0.0594 & 0.6348 & 1.126 & 0.690 & 1.838 \\
\hline ACT & Uncontrolled & 0.3272 & $0.0063^{*}$ & 1.924 & 1.203 & 3.077 \\
\hline Follow up with clinics & No & -0.2746 & $0.0328^{*}$ & 0.577 & 0.349 & 0.956 \\
\hline Education level & University & 0.4292 & $0.0071^{*}$ & 2.359 & 1.263 & 4.407 \\
\hline Educated about medication & No & 0.0790 & 0.5844 & 1.171 & 0.665 & 2.062 \\
\hline Educated about asthma & No & 0.2042 & 0.1506 & 1.504 & 0.862 & 2.625 \\
\hline
\end{tabular}

* Wald Chi-square statistic is significant at the .05 level. 
clinics at both institutions, as it was not the aim of the study. Another limitation is not comparing the risk factors of our patients to those patients who attend outpatient clinics; however, our previous study found that the majority of the patients at outpatient clinics still have uncontrolled asthma [26] and hold many false beliefs and misconceptions about bronchial asthma as a disease and the role of inhaled corticosteroids and the factors affecting compliance among adult asthmatic patients [33].

\section{Conclusion}

Our study has identified several factors that increase the risk of repeated ED visits for the crisis oriented care of asthma. The major factors we identified are a lack of asthma education, the lack of regular follow up with specialised asthma clinics, patient misunderstandings about the role of EDs in the treatment of bronchial asthma, and the underutilisation of inhaled steroid use. Most of these factors can be addressed by health care providers, and health care planners can rectify these problems by restructuring asthma management resources to emphasise a more multidisciplinary approach and invest in training additional asthma educators to participate in patient education and instruction of how to use inhaler devices and asthma action plans.

\section{Competing interests}

The authors declare that they have no competing interests.

\section{Authors' contributions}

$\mathrm{JH}$ : Review the scientific literature pertinent to the research question. Writing the proposal and responding to reviewer and IRB comments. Create data collection form and draft the first manuscript. AA: perform all statistical analysis and writ the result section. HA: Supervising the data collection at KAMC. SB:-Scientifically contribute to writing the proposal. HR: Supervising the data collection at KKUH. SA : Providing scientific expertise and operational guidance to data collection at KAMC and actively precipitating in contributing in the manuscript writing as per assignment by PI. MS: Scientifically contribute to writing the proposal and study conduct at KKUH. All authors read and approved the final manuscript.

\section{Acknowledgments}

We would like to thank Dr. Ali Al-Farhan and Dr. Raeied Hejaze for facilitating our access to the EDs and helping identify potential patients. We also thank King Abdullah International Medical Research Center (KAIMRC) for funding and provide editing supporting this research.

\section{Author details \\ 1Department of Medicine, Pulmonary Division-ICU, King Saud University for Health Sciences, Riyadh, Saudi Arabia. ${ }^{2}$ Department of Epidemiology and Biostatistics, College of Public Health and Health, Informatics, King Saud bin Abdulaziz University for Health Sciences, Riyadh, Saudi Arabia. ${ }^{3}$ Asthma Research Chair and Prince Naif Center for Immunology Research, \\ Department of Paediatrics, College of Medicine, King Saud University, Riyadh, Saudi Arabia. ${ }^{4}$ Head of Pulmonary Division, Medical Director of Sleep Disorders Center, Adjunct professor McGill University, King Saud University for Health Sciences, King Abdulaziz Medical City, Riyadh, Riyadh, Saudi Arabia.}

Received: 27 November 2012 Accepted: 14 December 2012 Published: 17 December 2012

\section{References}

1. Gupta RS, Weiss KB: The 2007 national asthma education and prevention program asthma guidelines: accelerating their implementation and facilitating their impact on children with asthma. Pediatrics 2009, 123(Suppl 3):S193-S198.

2. Al Frayh AR, Shakoor Z, Gad El Rab MO, Hasnain SM: Increased prevalence of asthma in saudi arabia. Ann Allergy Asthma Immunol 2001, 86(3):292-296

3. Al Frayh AR, Al Nahdi M, Bener AR, Jawadi TQ: Epidemiology of asthma and allergic rhinitis in two coastal regions of Saudi Arabia. Allerg Immunol (Paris) 1989, 21(10):389-393.

4. Adams RJ, Smith BJ, Ruffin RE: Factors associated with hospital admissions and repeat emergency department visits for adults with asthma. Thorax 2000, 55(7):566-573.

5. Weiss KB, Gergen PJ, Hodgson TA: An economic evaluation of asthma in the United States. N Engl J Med 1992, 326(13):862-866.

6. Abisheganaden J, Sin Fai Lam KN, Lim TK: A profile of acute asthma patients presenting to the emergency room. Singapore Med J 1996, 37(3):252-254.

7. Aelony $Y$ : Why patients with asthma go to the emergency room. JAMA 1980, 243(8):732

8. Al Zabadi H, El Sharif N: Factors associated with frequent emergency room attendance by asthma patients in Palestine. Int J Tuberc Lung Dis 2007, 11(8):920-927.

9. Berktas BM, Bircan A: Effects of atmospheric sulphur dioxide and particulate matter concentrations on emergency room admissions due to asthma in Ankara. Tuberk Toraks 2003, 51(3):231-238.

10. Chugh K: Acute asthma in emergency room. Indian J Pediatr 2003, 70(Suppl 1):S28-S33.

11. Dalcin PT, Piovesan DM, Kang S, Fernandes AK, Franciscatto E, Millan T, et al: Factors associated with emergency department visits due to acute asthma. Braz J Med Biol Res 2004, 37(9):1331-1338.

12. Dales RE, Schweitzer I, Kerr P, Gougeon L, Rivington R, Draper J: Risk factors for recurrent emergency department visits for asthma. Thorax 1995, 50(5):520-524

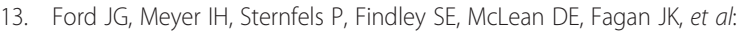
Patterns and predictors of asthma-related emergency department use in Harlem. Chest 2001, 120(4):1129-1135.

14. Garrett JE, Mulder J, Wong-Toi H: Characteristics of asthmatics using an urban accident and emergency department. N Z Med J 1988, 101(847 Pt 1):359-361

15. Hanania NA, David-Wang A, Kesten S, Chapman KR: Factors associated with emergency department dependence of patients with asthma. Chest 1997, 111(2):290-295.

16. Lee PY, Khoo EM: How well were asthmatic patients educated about their asthma? A study at the emergency department. Asia Pac J Public Health 2004, 16(1):45-49.

17. Rodriguez-Martinez CE, Sossa MP, Castro-Rodriguez JA: Factors associated to recurrent visits to the emergency department for asthma exacerbations in children: implications for a health education programme. Allergol Immunopathol (Madr) 2008, 36(2):72-78

18. Rossi OV, Kinnula VL, Huhti E: Emergency room visits for acute attacks of asthma: characterization of patients and visits. Respiration 1991, 58(1):21-25

19. Zeiger RS, Heller S, Mellon MH, Wald J, Falkoff R, Schatz M: Facilitated referral to asthma specialist reduces relapses in asthma emergency room visits. J Allergy Clin Immunol 1991, 87(6):1160-1168.

20. National Asthma Education and Prevention Program: Expert panel report 3. guidelines for the diagnosis and management of asthma. Bethesda (MD) national heart, lung, and blood institute. NIH Publication No. 07-4051. NIH Publication No 07-4051. 2007, http://www.nhlbi.nih.gov/guidelines/asthma/ asthgdln.pdf. Access date 02-12-2012.

21. Al-Moamary MS, Al-Hajjaj MS, Idrees MM, Zeitouni MO, Alanezi MO, Al-Jahdali HH, et al: The Saudi Initiative for asthma. Ann Thorac Med 2009, 4(4):216-233.

22. Bateman ED, Hurd SS, Barnes PJ, Bousquet J, Drazen JM, FitzGerald M, et al: Global strategy for asthma management and prevention: GINA executive summary. Eur Respir J. 2008, 31(1):143-78.

23. Clancy K: British guidelines on the management of asthma. Thorax 2004, 59(1):81-82 
24. Lababidi H, Hijaoui A, Zarzour M: Validation of the Arabic version of the asthma control test. Ann Thorac Med 2008, 3(2):44-47.

25. Malveaux FJ, Houlihan D, Diamond EL: Characteristics of asthma mortality and morbidity in African-Americans. J Asthma 1993, 30(6):431-437.

26. Al-Jahdali HH, Al-Hajjaj MS, Alanezi MO, Zeitoni MO, Al-Tasan TH: Asthma control assessment using asthma control test among patients attending 5 tertiary care hospitals in Saudi Arabia. Saudi Med J 2008, 29(5):714-717.

27. Pinto Pereira LM, Clement Y, Da Silva CK, McIntosh D, Simeon DT:

Understanding and use of inhaler medication by asthmatics in specialty care in Trinidad: a study following development of Caribbean guidelines for asthma management and prevention. Chest 2002, 121(6):1833-1840.

28. Adeyeye OO, Onadeko BO: Understanding medication and use of drug delivery device by asthmatic in Lagos. West Afr J Med 2008, 27(3):155-159.

29. Pinto Pereira L, Clement $Y$, Simeon D: Educational intervention for correct pressurised metered dose inhaler technique in Trinidadian patients with asthma. Patient Educ Couns 2001, 42(1):91-97.

30. Turktas H, Mungan D, Uysal MA, Oguzulgen K: Determinants of asthma control in tertiary level in Turkey: a cross-sectional multicenter survey. J Asthma 2010, 47(5):557-562.

31. Hanania NA, Wittman R, Kesten S, Chapman KR: Medical personnel's knowledge of and ability to use inhaling devices. Metered-dose inhalers, spacing chambers, and breath-actuated dry powder inhalers. Chest 1994, 105(1):111-116.

32. Abudahish A, Bella H: Primary care physicians perceptions and practices on asthma care in Aseer region, Saudi Arabia. Saudi Med J 2006, 27(3):333-337.

33. Al-Jahdali HH, Al-Zahrani Al, Al-Otaibi ST, Hassan IS, Al-Moamary MS, Al-Duhaim AS, et al: Perception of the role of inhaled corticosteroids and factors affecting compliance among asthmatic adult patients. Saudi Med J 2007, 28(4):569-573.

doi:10.1186/1471-2466-12-80

Cite this article as: AL-Jahdali et al:: Factors associated with patient visits to the emergency department for asthma therapy. BMC Pulmonary Medicine 2012 12:80.

\section{Submit your next manuscript to BioMed Central and take full advantage of:}

- Convenient online submission

- Thorough peer review

- No space constraints or color figure charges

- Immediate publication on acceptance

- Inclusion in PubMed, CAS, Scopus and Google Scholar

- Research which is freely available for redistribution 